\title{
Rancang Bangun Unipolar PWM Dilengkapi dengan Pengaturan Frekuensi Menggunakan Operational Amplifier
}

\author{
Asmar \\ Jurusan Teknik Elektro, Fakultas Teknik, Universitas Bangka Belitung \\ Email : asmarubb2@gmail.com
}

\begin{abstract}
Pulse Width Modulation (PWM) is applied to power electronic circuits for the control of converter circuits. In order to obtain good performance, the frequency of the PWM pulse must be adjusted to the type and parameter of the converter. In this study, the PWM pulses generated are unipolar PWM. Pulses are obtained by using three main circuits, namely triangular wave generator, control voltage and comparison circuit. The main component used is Operational Amplifier (Op-Amp). The resulting circuit can generate unipolar $\mathrm{PWM}$ pulses with frequency range $30 \mathrm{~Hz}$ to $5 \mathrm{kHz}$.
\end{abstract}

Keywords : Frequency, Op-Amp, Unipolar PWM

\section{INTISARI}

Pulse Width Modulation (PWM) diaplilaksikan pada rangkaian elektronika daya untuk pengendalian rangkaian konverter. Agar diperoleh kinerja yang baik, frekuensi pulsa PWM harus disesuaikan dengan jenis dan parameter konverter. Pada penelitian ini, pulsa PWM yang dihasilkan adalah unipolar PWM. Pulsa tersebut diperoleh dengan menggunakan tiga rangkaian utama, yaitu pembangkit gelombang segitiga, tegangan kontrol dan rangkaian pembanding. Komponen utama yang digunakan adalah Operational Amplifier (Op-Amp). Rangkaian yang dihasilkan dapat membangkitkan pulsa unipolar PWM dengan rentang frekuensi $30 \mathrm{~Hz}$ sampai dengan $5 \mathrm{kHz}$.

Kata kunci: Frequensi, Op-Amp, Unipolar PWM

\section{PENDAHULUAN}

Pulse Width Modulation (PWM) adalah metode pembangkitan pulsa dengan membandingkan gelombang segitiga dengan suatu tegangan kontrol berupa gelombang DC murni. Pulsa PWM digunakan untuk mengendalikan rangkaian konverter yaitu dengan mengubah lebar pulsa. Perbandingan lebar pulsa dengan periode pulsa dikenal dengan faktor kerja pulsa yang menentukan kondisi on dan off komponen elektronika daya [1],[2],[3].

Agar diperoleh kinerja konverter yang baik, frekuensi pulsa $P W M$ harus disesuaikan dengan komponen-komponen penyusun konverter. Selain itu, metode pengendalian konverter dengan $P W M$ juga harus mempertimbangkan jenis konveter. Pada $D C$-DC converter yang menggunakan $\mathrm{H}$ Bridge, pengendaliannya dapat menggunakan metode bipolar $P W M$ atau unipolar PWM.
Pengendalian dengan unipolar PWM akan memberikan kinerja yang lebih baik karena faktor riaknya lebih kecil dibandingkan dengan pengendalian menggunakan bipolar PWM [1],[2],[3].

Penelitian ini merupakan lanjutan penelitian sebelumnya [4] tetapi telah dikembangkan sehingga diperoleh pulsa PWM yang dihasilkan dapat diatur pada berbagai rentang frekuensi. Rangkaian yang dihasilkan dapat digunakan untuk berbagai percobaan untuk pengendalian $D C-D C$ converter.

\section{METODE PENELITIAN}

Metode pembangkitan pulsa unipolar PWM diperlihatkan pada Gambar 1. Untuk membangkitkan pulsa unipolar PWM dibutuhkan tiga buah rangkaian utama yaitu pembangkit gelombang segitiga, tegangan kontrol, dan 
Jurnal ECOTIPE, Volume 6, No.1, April 2019, Hal. 20-23

p-ISSN 2355-5068, e-ISSN 2622-4852

DOI: 10.33019/ecotipe.v6i1.942

pembanding. Frekuensi pulsa yang dihasilkan dipengaruhi oleh gelombang segitiga sedangkan faktor kerja pulsa dipengaruhi oleh tegangan kontrol.

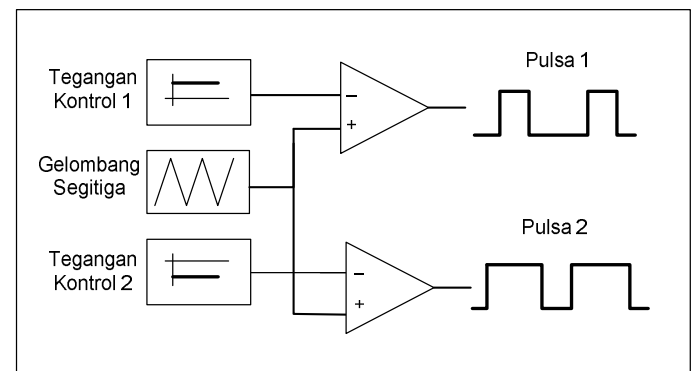

Gambar 1. Pembangkitan pulsa unipolar PWM

Gelombang segitiga dapat dihasilkan dengan mengkaskade osilator relaksasi dengan integrator [5]. Osilator relaksasi dan integrator tesebut dapat dibuat dengan Op-Amp. Rangkaian untuk membangkitkan gelombang segitiga dipelihatkan pada Gambar 2. Frekuensi gelombang segitiga dipengaruhi oleh nilai kapasitansi kapasitor dan setelan trimpot TR2.

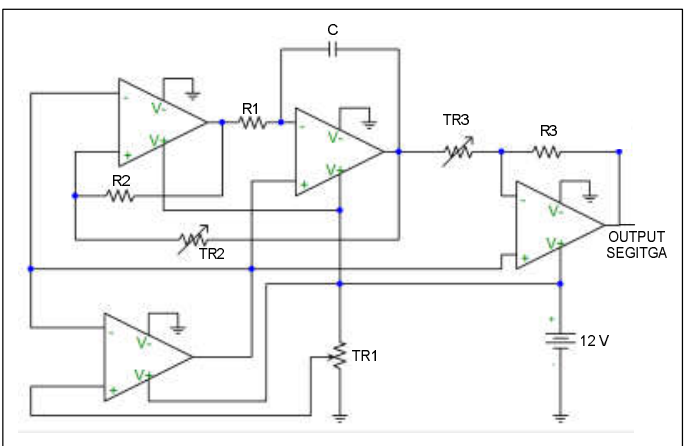

Gambar 2. Rancangan pembangkit gelombang segitiga

Pada rangkaian tegangan kontrol (terlihat pada Gambar 3), perubahan faktor kerja pulsa dilakukan melalui potensio. Tegangan kontrol kedua diperoleh dengan memperkuat tegangan kontrol pertama dengan penguatan sebesar -1. Agar posisi potensio dapat digunakan $100 \%$, maka nilai maksimum dan minimum tegangan kontrol harus disesuaikan dengan nilai maksimum dan minimum gelombang segitiga. Penyesuaian nilai maksimum dan minimum tersebut diatur melalui trimpot TR3, TR4, dan TR5.

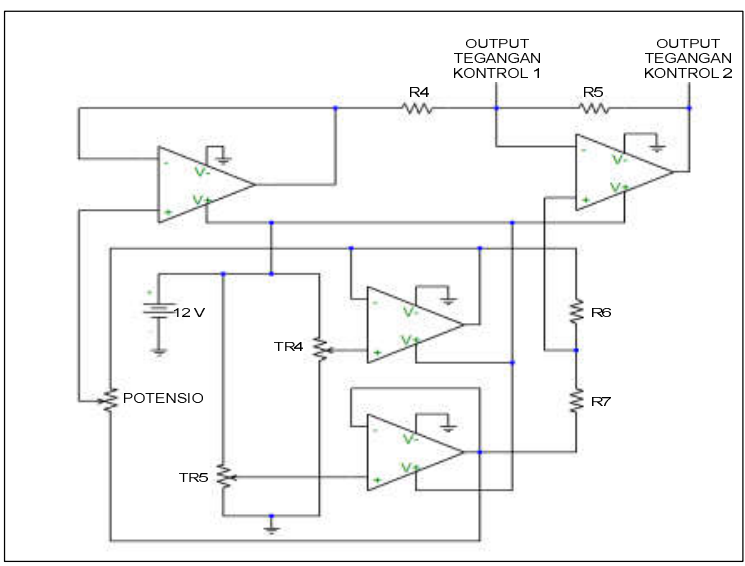

Gambar 3. Rancangan rangkaian tegangan kontrol

Keluaran dari rangkaian pembangkit gelombang segitiga dan tegangan kontrol merupakan masukan rangkaian pembanding (terlihat pada Gambar 4). Dengan mengubah nilai kapasitansi kapasitor dan menyetel posisi trimpot TR2 maka diperoleh pulsa PWM pada berbagai rentang frekuensi.

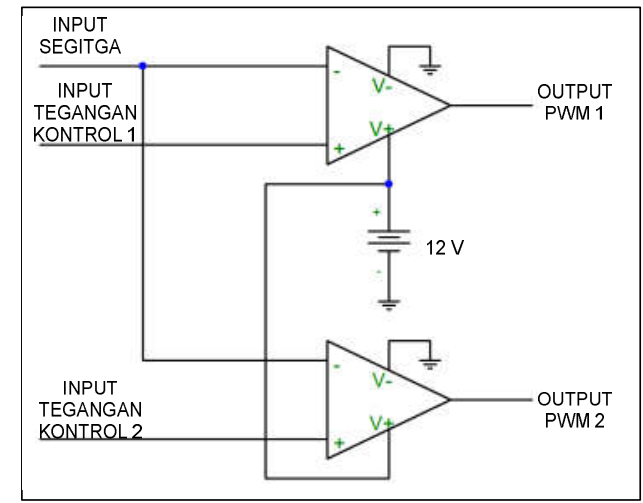

Gambar 4. Rancangan rangkaian pembanding

\section{HASIL PENELITIAN DAN ANALISIS}

Komponen Op-Amp yang digunakan untuk implementasi rancangan adalah LM 324. Komponen tersebut dapat bekerja pada tegangan $3 \mathrm{~V}$ sampai dengan 30V. Nilai-nilai resistansi resistor, trimpot, dan potensio yang digunakan pada rangkaian adalah $100 \mathrm{k} \Omega$. Frekuensi gelombang segitiga diperoleh dengan menggunakan kapasitor $0.1 \mathrm{uF}, 0.033 \mathrm{uF}, 0.01 \mathrm{uF}$, $0.0033 \mathrm{uF}$, dan $0.001 \mathrm{uF}$. Pada setiap nilai kapasitor tersebut, perubahan rentang frekuensi yang dihasilkan dengan penyetelan posisi trimpot TR2 adalah : 
1. Kapasitor $0.1 \mathrm{uF}$, frekuensi pulsa antara $30 \mathrm{~Hz}$ sampai dengan $250 \mathrm{~Hz}$

2. Kapasitor $0.033 \mathrm{uF}$, frekuensi pulsa antara $100 \mathrm{~Hz}$ sampai dengan $700 \mathrm{~Hz}$

3. Kapasitor 0.01uF, frekuensi pulsa antara $0.25 \mathrm{kHz}$ sampai dengan $2 \mathrm{kHz}$

4. Kapasitor $0.0033 \mathrm{uF}$, frekuensi pulsa antara $0.85 \mathrm{kHz}$ sampai dengan $5 \mathrm{kHz}$

Untuk ukuran kapasitor $0.001 \mathrm{uF}$, gelombang segitiga yang dihasilkan mengalami distorsi yang cukup besar sehingga Pulsa PWM yang dihasilkan tidak sesuai dengan yang diharapkan.

Gambar 5 memperlihatkan hasil simulasi untuk nilai kapasitor $0.01 \mathrm{uF}$, TR2 disetel pada posisi $50 \%$, dan potensio pada nilai $20 \%$. Hasil perbandingan pulsa segitiga dan tegangan kontrol memberikan pulsa unipolar PWM dengan frekuensi sekitar 50Hz. Faktor kerja pulsa PWM 1 sekitar 20\% dan pulsa PWM 2 sekitar $80 \%$.
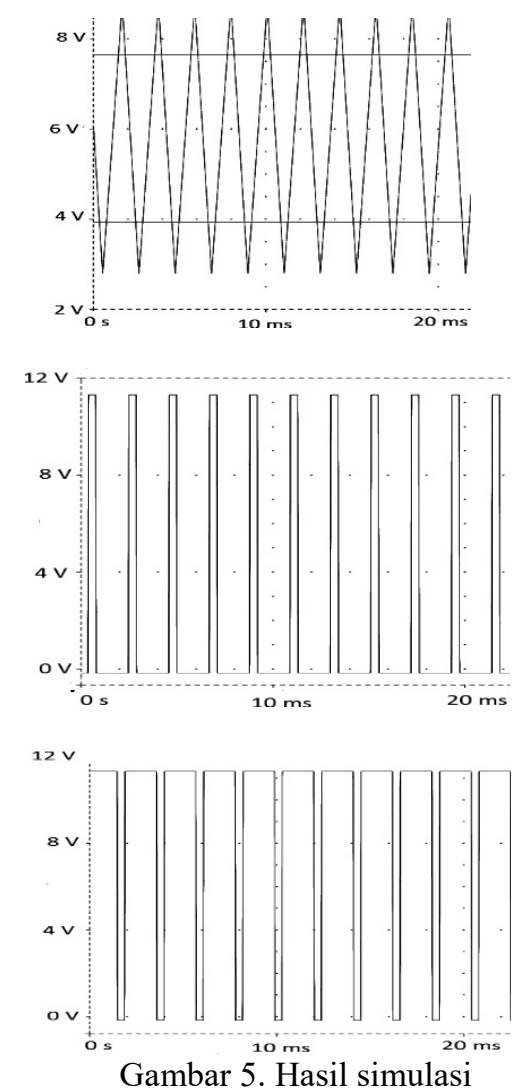

Penyetelan trimpot TR2 untuk menghasilkan rentang frekuensi juga memberikan hasil yang cukup baik. Salah satunya diperlihatkan pada Gambar 6. Walaupun perubahannya tidak linier secara keseluruhan tetapi posisi penyetelan trimpot TR2 seluruhnya dapat dimanfaatkan dan sensitivitasnya cukup baik.

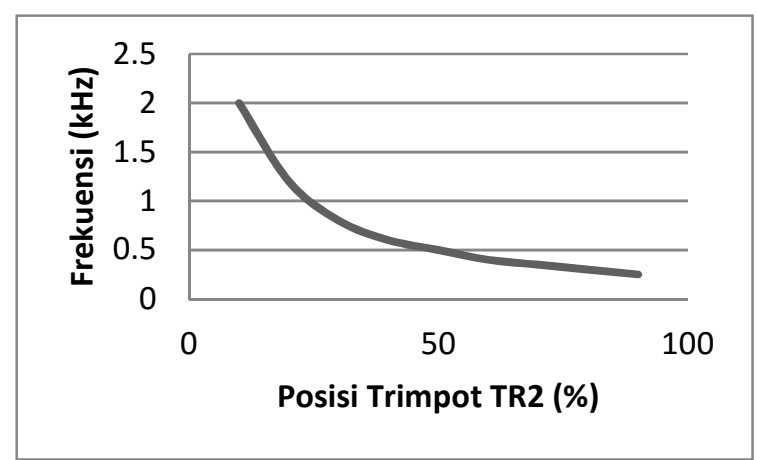

Gambar 6. Pengaruh penyetelan trimpot TR2 terhadap frekuensi untuk ukuran kapasitor $0.01 \mathrm{uF}$

Pada aplikasi DC-DC converter menggunakan H-Bridge untuk mengatur kecepatan motor DC, frekuensi pulsa pengontrolan umumnya pada orde ratusan Hertz. Dari hasil di atas, ukuran kapasitor yang sesuai adalah 0,01 uF. Untuk ukuran kapasitor $0.1 \mathrm{uF}$, frekuensi yang dihasilkan dapat digunakan untuk Square Wave Converter. Sedangkan untuk ukuran kapasitor $0.0033 \mathrm{uF}$, frekuensi pulsa dapat digunakan untuk pengontrolan Buck, Boost, dan Buck-Boost converter.

Hasil implementasi rancangan diperlihatkan pada Gambar 7 dan 8. Pengukuran yang diperoleh dari implementasi rancangan relatif sama dengan hasil simulasi. Hasil pengukuran dengan osiloskop untuk nilai kapasitor $0.01 \mathrm{uF}$, penyetelan trimpot TR2 pada posisi $50 \%$, dan potensio pada nilai $20 \%$ dipelihatkan pada Gambar 9.

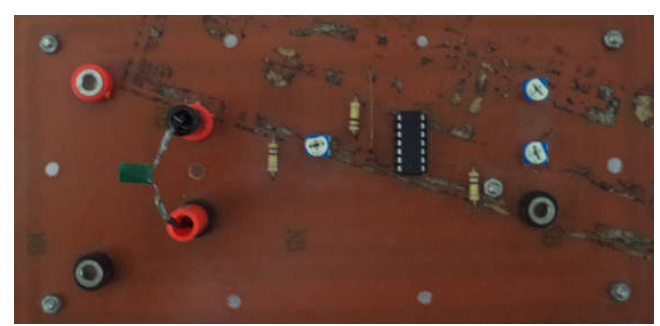

Gambar 7. Rangkaian pembangkit segitiga

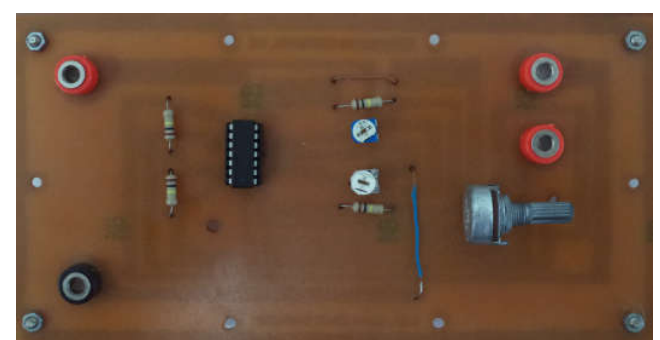

Gambar 8. Rangkaian tegangan kontrol 


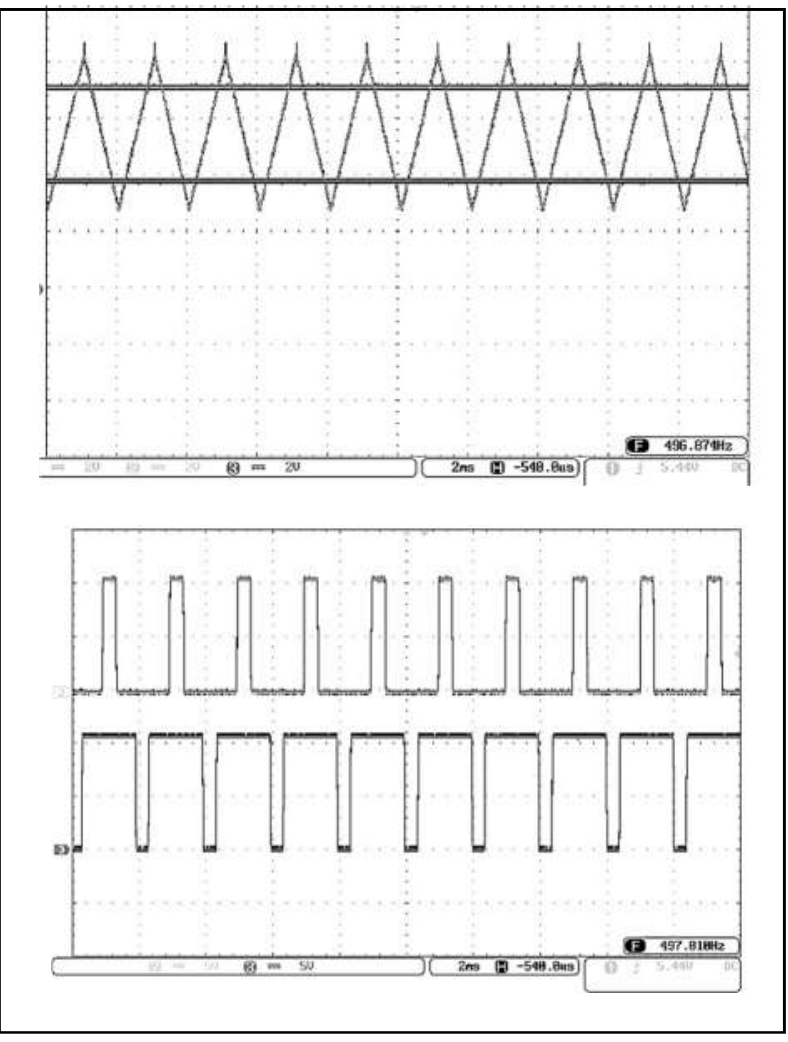

Gambar 9. Hasil pengukuran osiloskop

\section{KESIMPULAN}

Pulsa PWM dapat diperoleh menggunakan OpAmp yang difungsikan sebagai pembangkit gelombang segitiga, pengatur tegangan kontrol, dan pembanding. Frekuensi pulsa dapat diatur pada berbagai rentang frekuensi sesuai dengan nilai kapasitor digunakan. Nilai kapasitor dari hasil penelitian berkisar antara $0.1 \mathrm{uF}$ sampai dengan $0.0033 \mathrm{uF}$, dengan rentang frekuensi $30 \mathrm{~Hz}$ sampai dengan $5 \mathrm{kHz}$.

\section{SARAN}

Hasil yang diperoleh dapat dikembangkan untuk penelitian rangkaian kendali unipolar PWM yang dilengkapi dengan pengontrolan dead time sehingga kinerja komponen elektronika daya akan semakin baik.

\section{DAFTAR PUSTAKA}

[1] Hart, D.W. (1997). Introduction to Power Electronics. Prentice-Hall International, Inc., Indiana.

[2] Mohan, Undeland, Robbins. (1995). Power Electronics, Second edition. John Wiley \&Sons Inc., Singapore.

[3] Rashid, M.H. (1988). Power Electronics: Circuits, Devices and Application. PrenticeHall, Inc., New Jersey.

[4] Asmar (2014). Rancang Bangun Unipolar PWM untuk Pengendalian Rangkaian $\mathrm{H}$ Bridge Menggunakan Operational Amplifier. Jurnal ECOTIPE Vol.1 No.1 April 2014, Teknik Elektro Universitas Bangka Belitung.

[5] Zuhal, Zhanggischan (2004). Prinsip Dasar Elektroteknik. Gramedia Pustaka Utama, Jakarta. 